\title{
Nail-patella-like renal disease
}

INSERM

\section{Source}

INSERM. (1999). Orphanet: an online rare disease and orphan drug data base. Nailpatella-like renal disease. ORPHA:2613

Nail-patella-like renal disease is a severe nephropathy characterised by renal dysfunction, proteinuria, oedema and microscopic haematuria. It has been described in three brothers, two of which died from end-stage renal insufficiency. 